(described here by Webb et al.) - and the west where detailed work on well-dated sites (Baker) is still required. The deficiency is remedied in part by the successful studies on packrat (Neotoma) middens (Spaulding et al.), though this work too needs to be extended beyond the south-west.

In a similar vein, the advance of montane ice is less well documented than that of the continental ice-sheet: in general the onset and decline of montane glaciation runs ahead of the continental ice-sheet, no doubt because of the lagged response of the latter to climatic change.

Of further importance in establishing time-transgressive events for use in climatic modelling are data showing falling pluvial lake levels some 13,000 years ago in the southern Basin and Range, but not until the end of the Pleistocene farther north (Smith and Street-Perrot). It is difficult to disagree with R.G. Barry in his call for the collection of even more accurately dated data as a prelude to realistic modelling of the contemporary atmosphere.

All will welcome the first major synthetic treatise on the Holocene - from the latest assembly of palaeoecological data on vegetational history (discussed, for example, by Heusser), at first colonizing, later in dynamic equilibrium and subsequently coping with a cooling which culminated in renewed montane glaciation (Burke and Birkland); to models of alluvial history reconciling vegetation and climate (Knox); to the pragmatic and careful evaluation of Kutzbach on climatic change; and to a review of archaeology (Aikens).

These two volumes follow in the tradition of The Quaternary of the United States (Princeton University Press, 1965). But times have changed. The books focus on the past 25,000 years only, a necessity arising from the vast array of data available, but also because of the relatively good dating controls available for that period. The restriction is also in part a response to the high level of sophistication now demanded of Quaternary data. This places the earlier Wisconsinan (last glaciation) and Last Interglacial in a somewhat depressing light, to say nothing of the Quaternary terra incognita before that time. Perhaps it will be one of the many triumphs of the present volumes that, as well as catalysing further work on the late Quaternary, they may focus some attention on the seemingly intractable problems of that earlier time - without the solution of such problems, the absence of a full explanation of the dynamics of atmospheric-oceanic-continental interaction through time will continue to frustrate full understanding of even the late Quaternary and the projection of its climatic trends to the future. Happily these new volumes will provide a visionary nudge forward along these highways.

D.Q. Bowen is Professor of Physical Geography, The University College of Wales, Aberystwyth.

\section{Alternative forms in bioenergetics}

\section{Hans V. Westerhoff}

Physics of Bioenergetic Processes.

By L.A. Blumenfeld.

Springer-Verlag: 1984. Pp.132. DM 70, $\$ 27.20$.

RATHER than writing a much-needed handbook on our knowledge of physics as applied to bioenergetics, Professor Blumenfeld claims that enzymic catalysis cannot be satisfactorily accounted for by the current principles of physical chemistry. He rejects the relevance of one of those principles - the Eyring equation - for enzyme reactions, as it assumes equilibrium between the transition state complex and substrate-plus-enzyme. Experimental evidence is reviewed indicating that shortly after undergoing a chemical transition from $E$ to $E^{-}$, the conformation of an enzyme may still correspond to the equilibrium conformation of state $\mathrm{E}$. Because this conformation generally does not correspond to the most stable conformation for state $\mathrm{E}^{-}$, the enzyme will relax to a new conformation, $\mathrm{E}^{-*}$. The transition state, says Blumenfeld, thus cannot be described as having an enzyme in a conformation defined by its chemical state. As an alternative, he proposes to describe conformational relaxation in mechanical terms.

In the usual - and quite successful approach, the two states $\mathrm{E}^{-*}$ and $\mathrm{E}$ are just included as separate states in the des-

\section{Selected theory}

\section{Mark Ridley}

Conceptual Issues in Evolutionary

Biology: An Anthology.

Edited by Elliott Sober.

MIT Press: 1984. Pp.725. Hbk \$40, £38;

pbk \$19.95, £18.95.

WHAT is our modern philosophy of evolution? To judge from the generous, and, I think, representative selection of previously published works in Elliott Sober's anthology, it is mainly concerned with the "designful" properties of organisms their adaptations - and with Darwin's explanation of adaptation, natural selection.

The most damaging philosophical criticism of Darwin's theory is that it does not explain adaptation at all. Natural selection, in Spencer's form, "the survival of the fittest", has often been said to be a circular argument; but all the relevant authors in this anthology would disagree. The point is here most clearly made by Gould. "Fitness" has two meanings: the number of offspring on average left by a type, and cription. It is characteristic of the book as a whole that Blumenfeld does not explain why such a treatment would fail.

The author also calculates that, for a gas engine of molecular dimensions, the information-energy needed to move the piston at zero rate would exceed the amount of work done. Thus molecular machines could not operate reversibly. Here, the flaw in the argument lies in the strictly mechanical interpretation of reversibility; reversibility merely implies that the ensemble (time) average of the piston movement is zero. Individual pistons may fluctuate rapidly. A similar snag is evident in Blumenfeld's alternative theory for energy transduction, which at the level of a single particle in a quantum mechanical box uses Newton's action = -reaction law.

The review sections in the book provide new information only where they describe results previously published in Russian. That information is useful, but it is clear that the internal inconsistencies in the chemiosmotic coupling theory suggested by Blumenfeld exist only in his interpretations of that theory. With respect to external inconsistencies, it is not news that the chemiosmotic theory does not survive all experimental tests.

Although slow conformational changes may prove to have a role in bioenergy transduction, Blumenfeld's assertion that already established physical chemical theories could not account for them is unconvincing. His alternative theory is even less so.

Hans $V$. Westerhoff is a visiting scientist at the National Institutes of Health, Bethesda, Maryland.

how well designed, in the engineer's sense, the type is. The fitness of an eye can be considered optically as well as reproductively, and in Darwin's theory the latter is the cause (but not the criterion) of the former. If anything, I found five papers spread through 80 pages too large a dinner, but this is the one part of a subject, often criticized for its interminable and sterile controversies, on which all the professionals now agree. Let us indulge the celebration.

If natural selection does explain adaptation, we can proceed to three more questions. For the benefit of what kind of entities does natural selection produce adaptations? How well adapted are those entities? What kind of explanation is it? Now the disagreement begins. The first question is professionally phrased as "What is the unit of selection?". The main answers on offer are the gene, the organism and the group; and the main controversy concerns Williams and Dawkins's argument in favour of the gene. Fifteen pages of Dawkins (no Williams) stand against 95 from Gould, Lewontin, Sober and Wimsatt who variously argue for selection at "higher levels"; but unfortunately the 